\title{
EFFECTS OF UV-B ON PHOTOSYNTHETIC PARAMETERS, LIPID PEROXIDATION, FLAVONOIDS AND GROWTH TRAITS OF CONOCARPUS LANCIFOLIUS (ENGL.)
}

\author{
Patrice Suleman, Amina Redha, Mohamad Afzal and Redha Al-Hasan \\ Department of Biological Sciences, Faculty of Science, Kuwait University, P.O Box 5969, Safat 13060, Kuwait
}

Received 2013-11-11; Revised 2013-12-22; Accepted 2013-12-23

\begin{abstract}
Conocarpus lancifolius is a perennial ornamental plant adapted to the semi-arid conditions of Kuwait. It accumulates most of its biomass during the stressful summer conditions which includes UV-B irradiation. The study evaluated equivalent UV-B irradiation intensities that plants would normally experience sometime during the course of a year in Kuwait. Leaf area, plant height, photosynthetic parameters, Lipid Peroxidation (LP) and Phenyl Alanine Lyase (PAL) were measured in C. lancifolius plants exposed to different UV-B treatments. UV-B treatments decreased leaf area and plant height but induced the formation of lateral branches. Chlorophyll content, photosynthesis, chlorophyll fluorescence measured as maximum quantum efficiency of photosystem II (Fv/Fm) and Electron Transport Rate (ETR) decreased in the short term or the first 10-20 days after treatment. Lipid Peroxidation (LP) measured in terms of Malondiadehyde (MDA) content decreased in the long term after a short term increase but Phenyl Alanine Lyase (PAL) activity increased linearly by 41.2, 66.8 and $78.6 \%$ after 30 days. There was also Positive Linear Correlation between UV-B dosage and total flavonoid accumulation which was localized in epidermal cell walls, trichomes and cuticular layer. The response of $C$. lancifolius to ameliorate and/or tolerate UV-B stress involved multiple mechanisms that included increased concentrations of PAL activity, increased flavonoids production; and reduced lipid peroxidation. The net effect of flavonoid accumulation and PAL enzyme activity probably contributed significantly to the protection or tolerance of the species to the effects of UV-B.
\end{abstract}

Keywords:UV-B Radiation, Chlorophyll Fluorescence, Phenyl Alanine Lyase, Flavonoids, Lipid Peroxidation

\section{INTRODUCTION}

Plants are more vulnerable to elevated levels of ultraviolet-B radiation because they require sunlight for photosynthesis but the degree of response to UV-B varies greatly among plant species. UV-B radiation as a stress factor affects plants in a number of ways including: Reduction in growth, damage to photosynthetic pigments and function, reduction of carbon dioxide assimilation, decrease proteins and hormonal systems (Hollosy, 2002). Plant growth is affected by the reduction of plant height, leaf area with concurrent increase in auxiliary branching, leaf curling and dry weight (Zhao et al., 2003). When UV-B tolerance limits are exceeded, leaf structure changes and biomass may decrease. UV-B radiation also induces oxidative stress by producing Reactive Oxygen Species (ROS) which react with lipids, pigment proteins and nucleic acids (Costa et al., 2002).

Some plants tolerate UV-B radiation by structural modifications such as development of cuticular waxes and trichomes that act as sunscreen or attenuate UV-B (Krauss et al., 1997; Kakani et al., 2003), production of compounds such as flavonoids to filter out or absorb UV-B (Ravindran et al., 2010), antioxidants to neutralize free radicals (Li et al., 1993; Agrawal and Mishra, 2008), Corresponding Author: Redha Al-Hasan, Department of Biological Sciences, Faculty of Science, Kuwait University, P.O Box 5969, Safat 13060, Kuwait 
reduction of leaf area to minimize exposure to UV-B and increase in leaf thickness to increase the path of penetration (Zhao et al., 2003). A primary site for UV-B damage in plants is the chloroplast. Thus, measurement of UV-B absorbing pigments such as chlorophyll content and chlorophyll fluorescence and carotenoids have been used to determine the sensitivity of plant species to UVB (Agrawal and Rathore, 2007; Kumari and Agrawal, 2010). Lipids may also be damaged by UV-B radiation but the effects on thylakoid lipids and chlorophyll fluorescence is still debatable. Currently, there are a number of the reasons for differential response among plant species to UV-B. Midgley et al. (1998) suggested that the effects of UV-B may even be cumulative.

Conocarpus lancifolius was introduced into Kuwait as an ornamental plant. It accumulates most of its biomass during the stressful summer environmental conditions including UV-B radiation. The species is tolerant to drought, salinity and elevated temperature through a number of physiological and biochemical responses (Redha et al., 2012; Suleman et al., 2013). It also appears to tolerate UV-B radiation in semi-arid conditions but this has not been determined. Thus, the objective of this study was to evaluate changes in some growth traits, chlorophyll content, chlorophyll fluorescence (maximum quantum efficiency of photosystem II (Fv/Fm) and Electron Transport Rate (ETR), photosynthetic rate, lipid peroxidation and Phenyl Alanine Lyase (PAL) activity in C. lancifolius after exposure to UV-B radiation treatments.

\section{MATERIALS AND METHODS}

\subsection{Plant Material and Growth Conditions}

Single shoot plants of $C$. lancifolius at 14-15 leaf stage in two liter plastic pots with local sandy-loam soil were used. Control plants were placed in a growth chamber with fluorescent tubes photon flux of $400 \mu \mathrm{moL}$ $\mathrm{m}^{-2} \mathrm{~s}^{-1}$ PAR. UV-B treatments were conducted in walk-in growth chambers fitted with UV-B light tubes (TL01/40, Phillips, ND.) at $25^{\circ} \mathrm{C} \pm 1$ and $\mathrm{RH}$ of $40 \%$. Cellulose acetate film was used to remove radiation below $290 \mathrm{~nm}$. Adjusting the height of UV-B tubes allowed for plants to be irradiated at the plant canopy level for $6 \mathrm{~h}$ per day with 0.5, 1.0 and $2.0 \mathrm{Wm}^{-2}$ or ca. 1.8, 3.6 and $7.2 \mathrm{KJm}^{-2}$, measured with a radiometer, ELDONNET 2002, (ICT, Australia). UV-B treatment intensities were selected based on monthly mean UV-B radiation measurements in Kuwait. Plants in all treatments were maintained at field capacity.

\subsection{Plant Growth Measurements}

Plant growth was measured with respect to leaf area, plant height and number of lateral branches for
30 days. Leaf area was measured on young and expanding fourth and fifth leaves with a portable laser area meter (CI 203, Camas, WA, USA). Plant height from the soil line to shoot apex was determined using a one meter straight edge ruler.

\subsection{Chlorophyll Content Index, Chlorophyll Fluorescence and Photosynthesis Measurements}

Chlorophyll Content Index (CCI) of mature leaves was determined using a portable Chlorophyll Content Meter (CCM-200, OPTI-SCIENCES, Tyngsboro, MA, USA). Chlorophyll fluorescence measurements were performed for maximum quantum efficiency of PS II (Fv/Fm) and Electron Transport Rate (ETR) on three dark adapted (45 min) mature leaves from each plant to assess the status or efficiency of Photosystem (PS II) with a Chlorophyll Fluorometer OS5-FL (OPTI-SCIENCE, Hudson, NH, USA). The rate of photosynthesis was measured using LCi photosynthesis meter CI 340, (ADC BioScientific Ltd., Hoddesdon, UK). Treatments were replicated four times and measurements were taken from three mature leaves of each plant.

\subsection{Determination of Lipid Peroxidation}

Lipid peroxidation was determined in terms of Malondiadehyde (MDA) levels using modified Thiobarbitturic Acid Reactive-Substances (TBARS) assay as described by (Hodges et al., 1999). The absorbance of supernatants was measured at 440, 532 and $600 \mathrm{~nm}$ and used in the calculation of MDA equivalents.

\subsection{Localization and Measurement of Flavonoids and PAL Activity}

Leaf epidermal peels were used to determine the induction and localization of UV-B screening flavonoids using naturstoffreagenz A ( $\beta$-aminodiethylesther of diphenylboric acid, Sigma), $0.1 \% \mathrm{w} / \mathrm{v}$ in $96 \%$ methanol as described by Schnitzler et al. (1996). Epifluorescence microscopy of sections was performed using Zeiss Axioscope A1, with Axiocam HR3 camera. Fluorescence emission was with filter \#9 and the excitation wavelength was $488 \mathrm{~nm}$.

Flavonoids were determined using $1 \mathrm{~g}$ of the airdried ground leaf tissue in $80 \%$ methanol at room temperature for $12 \mathrm{~h}$. The extract was vacuum-filtered and the organic solvent was removed in a rotavapor leaving the aqueous phase that was removed by freeze-drying. The lyophilized sample was reconstituted in methanol and the total flavonoid content was determined using the aluminum chloride 
method (Curcic et al., 2012). Quercetin was used as a standard and results were expressed as milligram of quercetin equivalent per gram dry weight $\left(\mathrm{mg} \mathrm{QE} \mathrm{g}^{-1}\right.$ DW) of the plant material.

PAL was determined as described by Bruseke (1980). PAL activity was assayed spectrophotometrically by measuring trans-cinnamic acid formed at $290 \mathrm{~nm}$ and enzyme activity was expressed as $\mu$ mol t-cinnamic acid $\min ^{-1}$ gram $^{-1}$ protein.

\subsection{Statistical Analysis}

The experiment was done twice and treatments in each test were arranged in a randomized complete design. Unless stated in the text each treatment was replicated four times and data were collected from three mature leaves of each plant. The data were subjected to analysis of variance (ANOVA) at $\mathrm{P}=$ 0.05 level and means were separated with Duncan's Multiple Range Test (DMRT), Michigan State University Statistical software (MSTAT-C). Correlation was used to describe the relationship between (1) Total flavonoids accumulation and UV-B treatments and (2) PAL and lipid peroxidation.

\section{RESULTS}

\subsection{Plant Growth}

Leaf area for UV-B treatments was reduced by 14.2$15.5 \%$ (Table 1). Younger leaves (2-4) at $2.0 \mathrm{Wm}^{-2}$ were slightly curled or wrinkled and had few small necrotic spots. Plant height was reduced by $10.5-16.1 \%$ after 30 days and plants irradiated in 1.0 and $2.0 \mathrm{Wm}^{-2}$ UV-B developed 2-3 lateral branches.

\subsection{Chlorophyll Content Index (CCI), Photosynthesis and Chlorophyll Fluorescence}

Chlorophyll content was significantly reduced in UVB treatments after 5 days and plants at $2.0 \mathrm{Wm}^{-2} \mathrm{UV}-\mathrm{B}$ had the least CCI (Table 2). UV-B treated plants also showed significant reduction in photosynthesis (Fig. 1). After linear rate of decline for the 10-15 days, photosynthesis increased in UV-B treated plants but the values were still lower than the control. There was initial decrease and subsequent increase in maximum quantum efficiency of PSII (Fv/Fm), (Fig. 2) and Electron Transport Rate (ETR), (Table 2). Fv/Fm was not significantly different among UV-B treatments until after 10 days.

\subsection{Effect on MDA as an Index of Lipid Peroxidation (LP)}

MDA accumulation was optimum after 10-20 DAT and thereafter declined regardless of the dosage of UV-B radiation (Fig. 3). The initial effect of UV-B showed significant increase in MDA levels in all treaments. However, after 50 days (long term the MDA levels in plants exposed to 0.5 -1.0 UV-B were lower compared to the control.

\subsection{PAL Activity and Localization Flavonoids}

Plants exposed to UV-B treatments showed significantly linear increase in PAL activity (Fig. 4). PAL increased by $41.2,66.8$ and $78.6 \%$ in 30 days. Fluorescent microscopy of epidermal leaf peels stained with naturstoffreagenz A showed the presence of flavonoids by intense fluorescent yellowish-green and golden-yellow in cell walls and in the trichomes (Fig. 5a-d). Epidermal cell walls appeared thicker in UV-B exposed plants. There was a positive linear correlation between total flavonoid accumulated and UV-B levels (Fig. 6). The concentration of flavonoids plants irradiated with $2.0 \mathrm{Wm}^{-2}$ increased by $111.8 \%$ after 30 days.

The data also showed a curvilinear relationship between PAL and MDA (Fig. 7). MDA increased with increased PAL activity for 15 days (14.2 mmolmg ${ }^{-1} \mathrm{~min}^{-1}$ ) and thereafter a concurrent reduction in MDA level with increased PAL.

Table 1. Leaf area and plant height of $C$. lancifolius exposed to variable UV-B radiation in a growth chamber. Values represent means of data from 3 mature leaves taken from 4 replicates. Means in each column followed by the same letter are not significantly different according to Duncan's Multiple Range Test (DMRT) at P = 0.05

\begin{tabular}{|c|c|c|c|c|c|c|c|}
\hline \multirow{3}{*}{$\begin{array}{l}\text { Treatment } \\
\left(\mathrm{W} / \mathrm{m}^{2}\right)\end{array}$} & \multicolumn{3}{|c|}{ leaf area $\left(\mathrm{cm}^{2}\right)$} & \multicolumn{3}{|c|}{ Plant height $(\mathrm{cm})$} & No. of lateral branches \\
\hline & Days & & & Days & & & Day \\
\hline & 1 & 15 & 30 & 1 & 15 & 30 & 30 \\
\hline 0 & $20.9 a$ & $23.2 \mathrm{~b}$ & $24.9 \mathrm{~b}$ & $25.2 \mathrm{a}$ & $28.7 \mathrm{ab}$ & $32.3 b$ & 0 \\
\hline 0.5 & $20.3 \mathrm{a}$ & $20.5 \mathrm{a}$ & $21.4 \mathrm{a}$ & $25.5 \mathrm{a}$ & $27.1 \mathrm{a}$ & $28.9 \mathrm{a}$ & 0 \\
\hline 10 & $20.6 \mathrm{a}$ & $21.0 \mathrm{a}$ & $21.2 \mathrm{a}$ & $25.6 \mathrm{a}$ & $26.2 \mathrm{a}$ & $27.3 \mathrm{a}$ & 2 \\
\hline 2 & $20.7 \mathrm{a}$ & $20.9 a$ & $21.0 \mathrm{a}$ & $25.9 \mathrm{a}$ & $26.7 \mathrm{a}$ & $27.1 \mathrm{a}$ & 3 \\
\hline
\end{tabular}


Patrice Suleman et al. / American Journal of Agricultural and Biological Sciences 9 (1): 55-63, 2014

Table 2. Chlorophyll Content Index (CCI) and Electron Transport Rate (ETR) of matures leaves of C. lancifolius exposed to variable UV-B radiation in a growth chamber. Values represent means of data from 3 mature leaves taken from 4 replicates. Means in each column followed by the same letter are not significantly different according to Duncan's Multiple Range Test (DMRT) at $\mathrm{P}=0.05$

\begin{tabular}{|c|c|c|c|c|c|c|}
\hline \multirow{3}{*}{$\begin{array}{l}\text { Treatment } \\
\left.\mathrm{W} / \mathrm{m}^{2}\right)\end{array}$} & \multicolumn{3}{|l|}{ CCI } & \multicolumn{3}{|l|}{ ETR } \\
\hline & \multicolumn{3}{|l|}{ Days } & \multicolumn{3}{|l|}{ Days } \\
\hline & 1 & 15 & 30 & 1 & 15 & 30 \\
\hline 0 & $51.8 \mathrm{a}$ & $63.4 c$ & $69.2 d$ & $161.5 \mathrm{a}$ & $178.8 \mathrm{~d}$ & $181.7 \mathrm{~d}$ \\
\hline 0.5 & $52.2 \mathrm{a}$ & $46.8 b$ & $50.6 c$ & $162.9 \mathrm{a}$ & $154.9 \mathrm{c}$ & $160.1 \mathrm{c}$ \\
\hline 1 & $53.0 \mathrm{a}$ & $38.5 \mathrm{a}$ & $46.8 b$ & $160.3 \mathrm{a}$ & $146.7 \mathrm{~b}$ & $153.1 \mathrm{~b}$ \\
\hline 2 & $52.1 \mathrm{a}$ & $40.1 \mathrm{a}$ & $38.4 \mathrm{a}$ & $163.6 \mathrm{a}$ & $138.7 \mathrm{a}$ & $144.2 \mathrm{a}$ \\
\hline
\end{tabular}

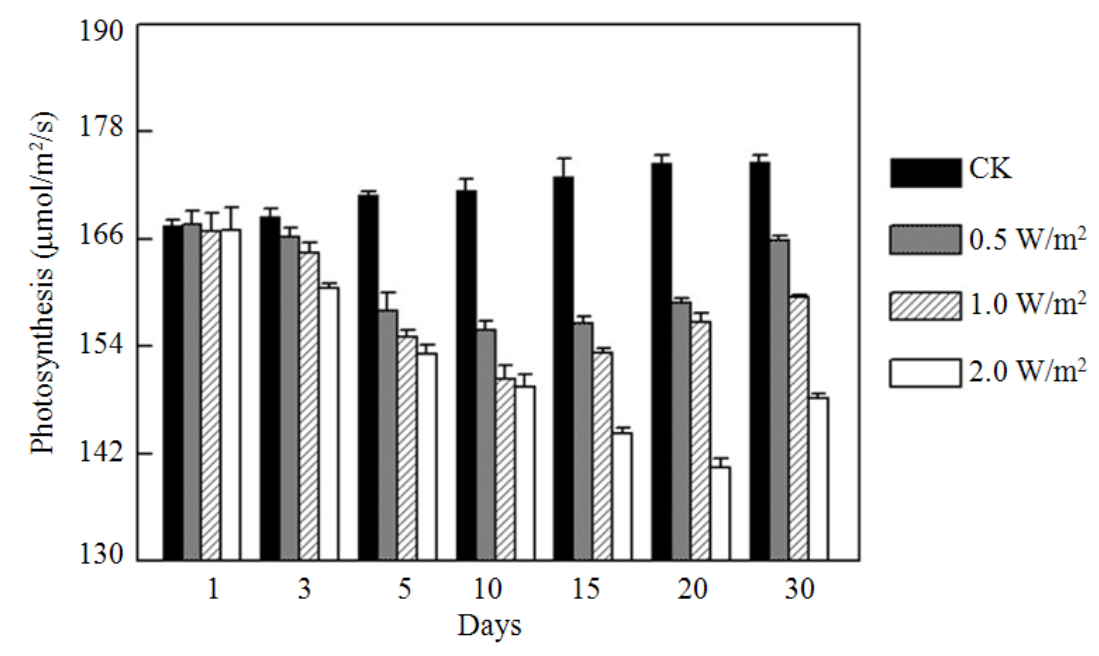

Fig. 1. Effect of different levels of UV-B radiation on photosynthesis in C. lancifolius for 30 days. Values represent means of data from 3 mature leaves taken from four replicates. Error bars $=$ Standard Error of the means

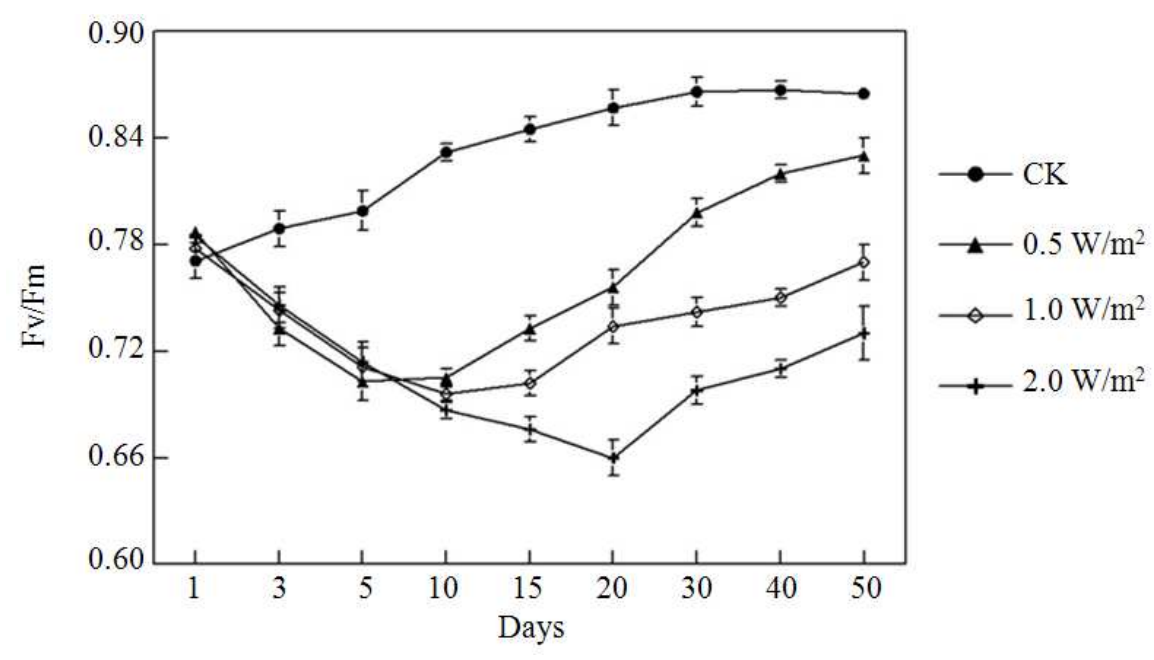

Fig. 2. Maximum photochemical efficiency (Fv/Fm) of PS II of C. lancifolius as affected by different UV-B levels for 30 days 
Patrice Suleman et al. / American Journal of Agricultural and Biological Sciences 9 (1): 55-63, 2014

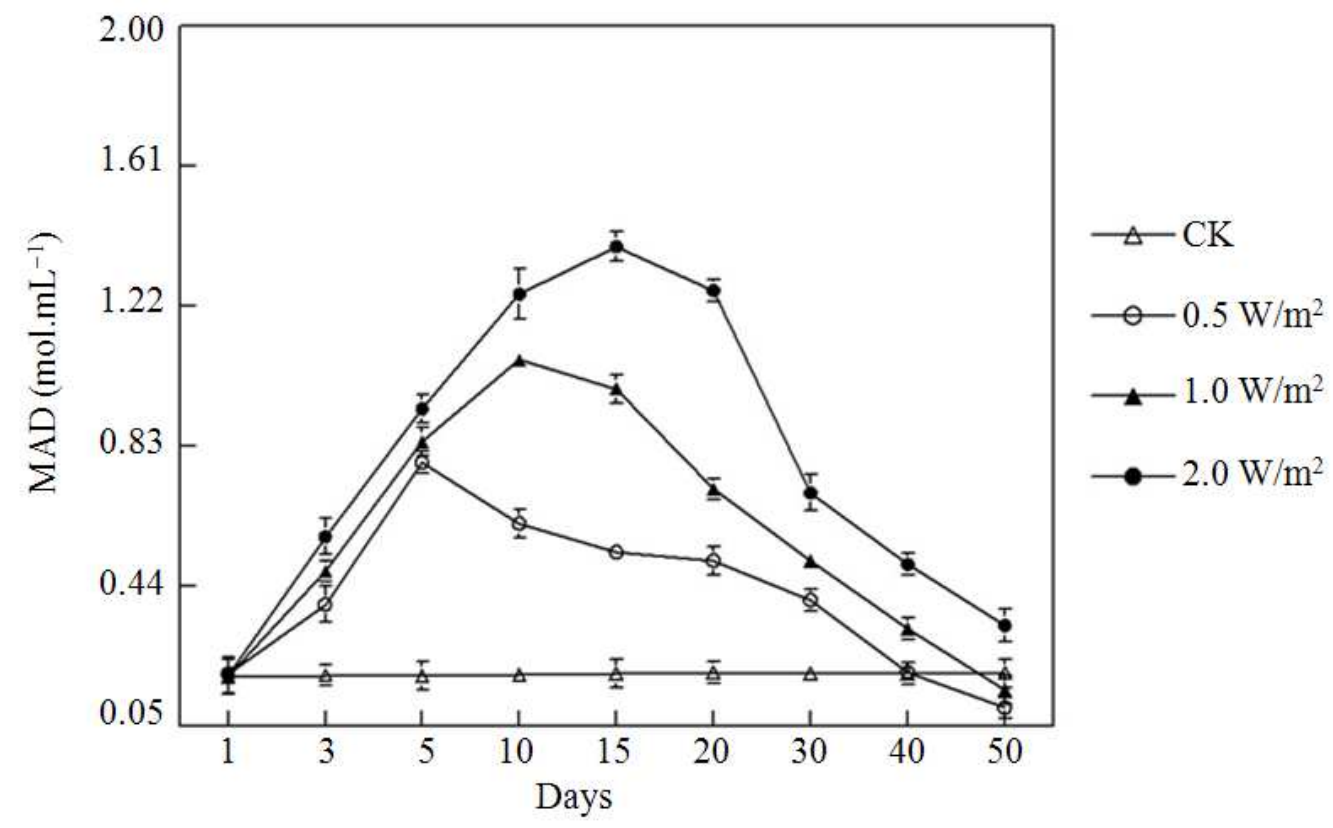

Fig. 3. Effect of UV-B radiation on lipid peroxidation Measured As Malondiadehyde (MDA) concentration in C. lancifolius for 50 days. Values represent means of data from 3 mature leaves taken from four replicates. Error bars $=$ Standard Error of the means

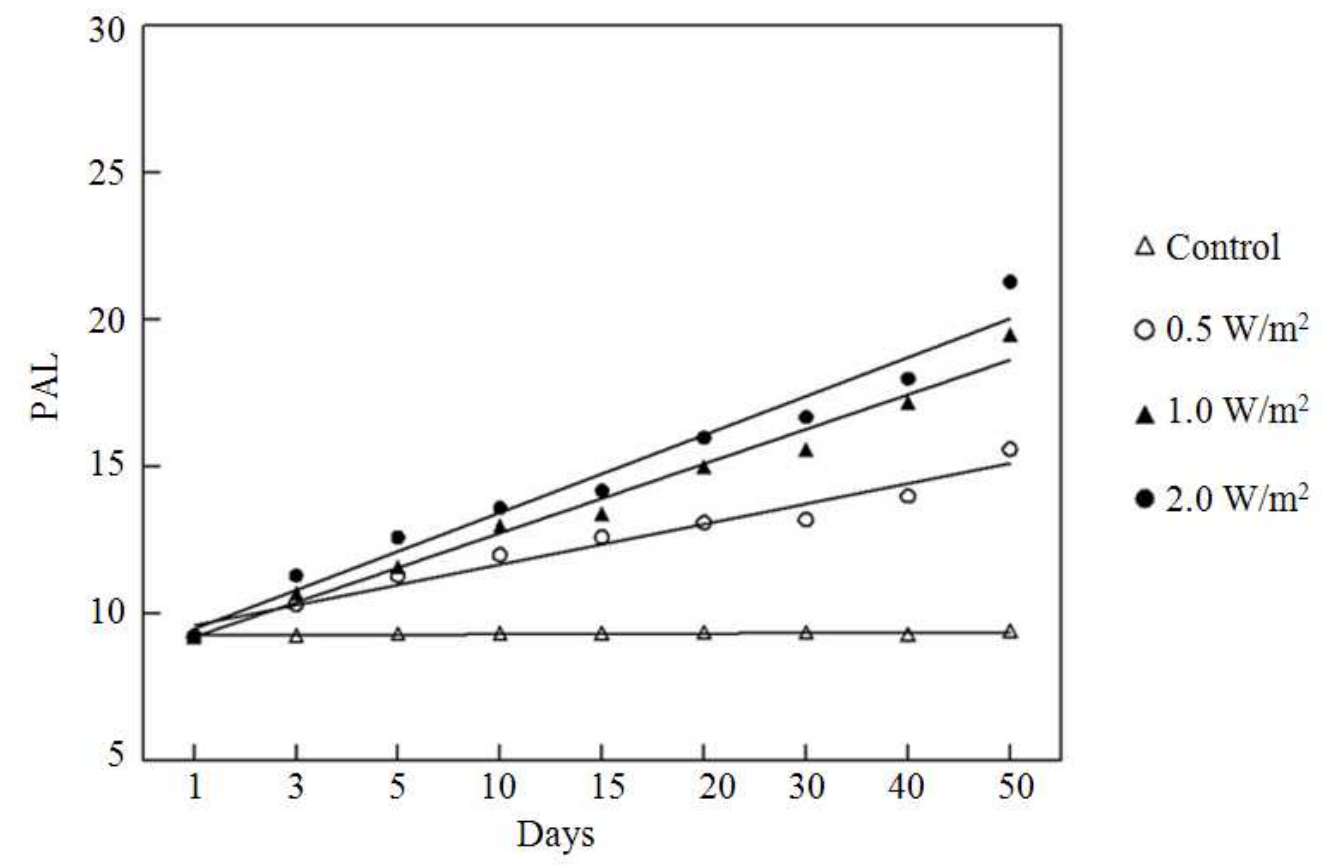

Fig. 4. Relationship between Phenyl Alanine Lyase (PAL) activity measured as trans-cinnamic acid formed at $290 \mathrm{~nm}$ and duration in C.lancifolius plants exposed to UV-B radiations for 50 days 


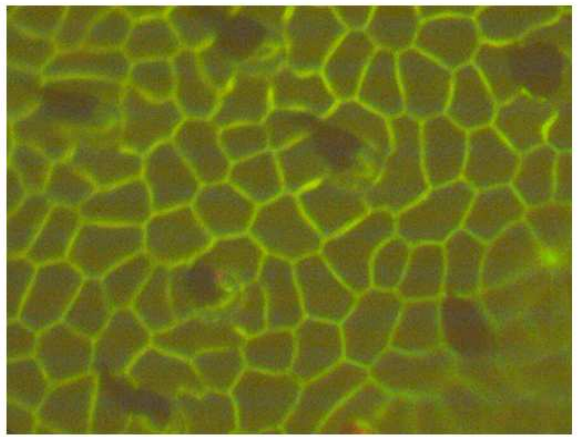

(a)

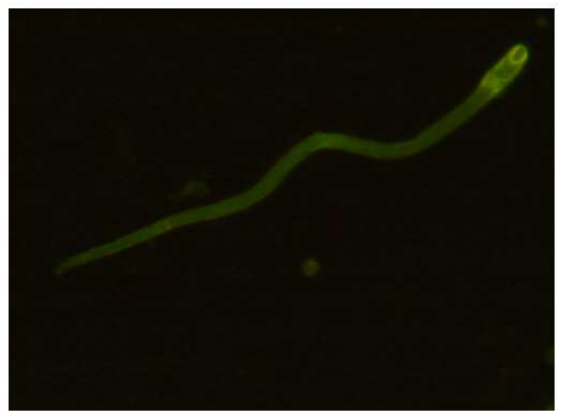

(c)

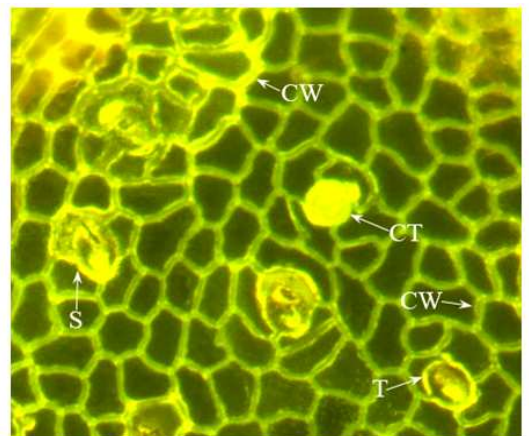

(b)

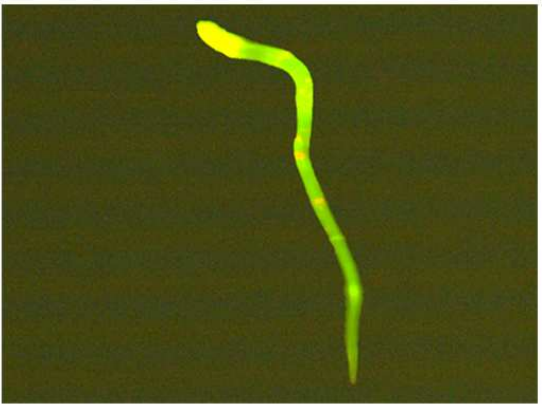

(d)

Fig. 5. Representative fluorescence images of epidermal peels showing localization of flavonoids due to exposure to UV-B radiation after 7 days: (a) epidermal cell walls of control leaf (b) epidermal cell walls of leaf exposed to $2.0 \mathrm{Wm}^{-2}$ of UV-B (c) a bulbous base a trichome of control and (d) a bulbous base a trichome from a leaf exposed to UV-B. $\mathrm{CW}=$ cell wall; $\mathrm{CT}=$ short capitate trichome; $\mathrm{T}=$ cut base of trichome; $\mathrm{S}=$ stomata, $\mathrm{x} 200$

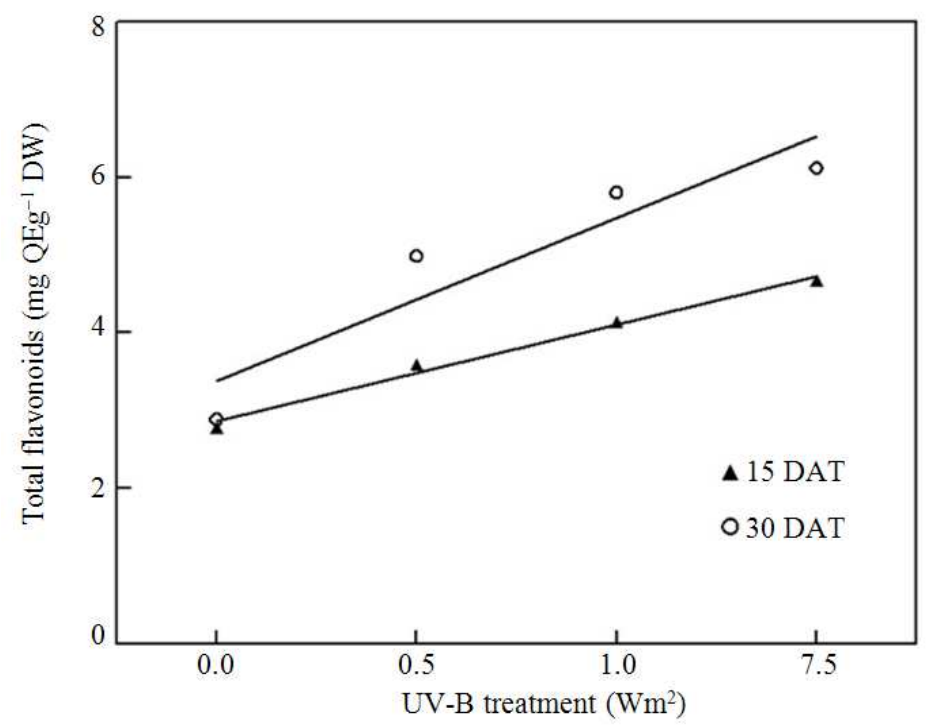

Fig. 6. Relationship between UV-B treatments and total flavonoid concentration in C. lancifolius plants after 15 and 30 days exposure. Linear relationships are represented by the equations: $y=0.60 x+2.33$; $\left(r^{2}=0.98\right)$ for 15 days and $y=1.05 x+2.33$; $\left(\mathrm{r}^{2}=0.86\right)$ for 30 days; where $\mathrm{y}=$ total flavonoids and $\mathrm{x}=\mathrm{UV}-\mathrm{B}$ treatments 


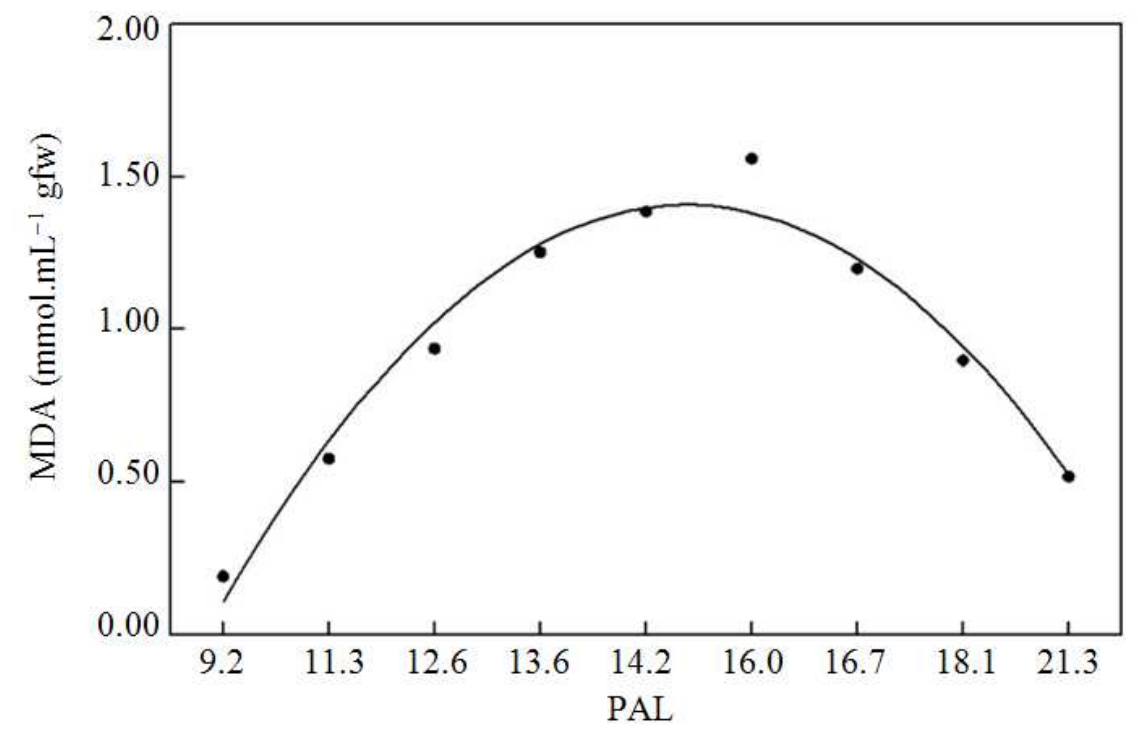

Fig. 7. Relationship between Phenyl Alanine Lyase (PAL) and MDA accumulation in C. lancifolius exposed to $2.0 \mathrm{Wm}^{-2} \mathrm{UV}-\mathrm{B}$. The curvilinear relationship is represented by equation $\mathrm{y}=-0.07 \mathrm{x}^{2}+0.73 \mathrm{x}-0.055, \mathrm{r}^{2}$ value $=0.96$; where $\mathrm{y}=\mathrm{MDA}$ and $\mathrm{x}=$ PAL activity measured after $1,3,5,10,15,20,30,40$ and 50 days. Values represent means of data from 3 mature leaves taken from four replicates

\section{DISCUSSION}

The study showed increased dosage of UV-B irradiation resulted in the reduction of leaf size and plant height however, the number of lateral branches increased in comparison to the control. Similar observations have been reported in other plant species (Kakani et al., 2003; Santos et al., 2004). Reduction in leaf area could be an adaptive process in order to reduce leaf exposure to UV$\mathrm{B}$ irradiation. Plant growth in response to stress may be influenced by other processes such lipid peroxidation caused by free radicals, cell division and protein synthesis, reduction in photosynthesis and efficiency of photosystem II (Jordan et al., 1992; Hollosy, 2002; Redha et al., 2012). CCI was significantly reduced for a short period regardless of the UV-B dosage in this study. Compared to the control; 2. $0 \mathrm{Wm}^{-2} \mathrm{UV}-\mathrm{B}$ treatment reduced CCI by $37.5 \%$. Ravindran et al. (2010) observed a $20.1 \%$ reduction in chlorophyll content after the application of supplemental UV-B to plants and that chloroplast is usually the first and major site of damage of UV-B radiation. In this study, regardless of UV-B dosage, irradiated plants showed an initial reduction of CCI; which increased thereafter. This is may be due to (1) initial low levels of UV-B absorbing pigments which increased with prolonged exposure to UV-B irradiation and/or (2) breakdown of pigments but not their precursors. Degradation of chlorophyll may also be due to the direct effect of UV-B or production of active oxygen species by UV-B (Agrawal and Mishra, 2008). In this study UV-B irradiation resulted in both the initial reductions of CCI and increase lipid peroxidation.

Reduction in photosynthesis was probably compensated for by additional leaves produced by increased number of lateral branches but recovery of photosynthesis was probably due to the accumulation of flavonoids localized in the epidermal cell walls. Flavonoids tend to attenuate or minimize the penetration of the UV-B (Smith et al., 2000) and the emission of yellowish-green and golden-yellow fluorescence in the cell walls indicated the presence of kaempferol and quercetin (Buer et al., 2007). Fifteen days after UV-B treatments $C$. lancifolious showed linear increase in flavonoid accumulation; which indicates that flavonoid production and accumulation during this exposure period may be proportional to UV-B intensity up to $2.0 \mathrm{Wm}^{-2}$.

The linear increase in PAL activity also suggests a tolerance response to UV-B which stimulated enzymes in the phenylpropanoid pathway resulting in flavonoid production (Wilson et al., 2001). The data and relationship between PAL and MDA also showed a threshold of PAL activity was required to reduce or ameliorate lipid peroxidation in $C$. lancifolius. 
UV-B treatments increased MDA levels for 20 days depending on the dose, followed by reduction to levels below that of control plants. MDA is widely used as a maker for oxidative lipid damage (Hernandez and Almansa, 2002) and the reduction in MDA levels after 15-20 days with increasing UV-B suggests $C$. lancifolius may have multiple mechanisms to ameliorate and/or tolerate UV-B stress.

\section{CONCLUSION}

This study showed that $C$. lancifolius plants exposed to different UV-B doses exhibited both short and long term responses with increased UV-B iiradiation. In this species, UV-B negatively affected the plant height and leaf area but not the development of lateral branches. UV-B effects. In the short term (5-20 days) included reductions in chlorophyll content as well as photosynthetic parameters and function. The damage due to UV-B was related to the effects on chlorophyll cont ent, maximum photochemical efficiency (Fv/Fm) and electron transport rate (ETR) of PSII that impacted the plant height and leaf size of the species. The growth and development of the species however, improved in the long term (20-50 days) probably due to decreased LP and PAL activities; and the accumulation of flavonoids that resulted in increased photosynthetic rate. The net effects of reduced LP, increased PAL activity and production of UV-B absorbing flavonoids probably contributed significantly to the amelioration and/or tolerance of $C$. lancifolius to UV-B stress.

\section{ACKNOWLEDGEMENT}

This study was supported by grants from Kuwait Foundation for Advancement of Sciences (KFAS), (no. 2011-1207-08). The authors are grateful to Mrs Divya Saju and Mrs Jacquilion Jose as Research Assistants and to PAAFR, Kuwait for providing planting material.

\section{REFERENCES}

Agrawal, S.B. and D. Rathore, 2007. Changes in oxidative stress defense system in wheat (Triticum aestivum L.) and mung bean (Vigna radiate L.) cultivars grown with and without mineral nutrients and irradiated by supplemental ultraviolet-B. Environ. Exp. Bot., 59: 21-23. DOI: 10.1016/j.envexpbot.2005.09.009

Agrawal, S.B. and S. Mishra, 2008. Effects of supplemental ultraviolet-B and cadmium on plant growth, antioxidants and yield of Pisum sativum L. Ecotoxicol. Environ. Safety, 72: 610-618. DOI: 10.1016/j.ecoenv.2007.10.007
Bruseke, C.H., 1980. Effect of UV-B radiation on leguminous plants. Physiol. Plant Pathol., 16: 409-412.

Buer, C.S., G.K. Muday and M.A. Djorjevic, 2007. Flavanoids are differentially taken up and transported long distances in Arabidopsis. Plant Physiol., 145: 478-490. DOI: 10.1104/pp.107.101824

Costa, H., S.M. Gallego and M.L. Tomaro, 2002. Effects of ultraviolet radiation on antioxidant defense system of sunflower cotyledons. Plant Sci., 162: 939-945. DOI: 10.1016/S0168-9452(02)00051-1

Curcic, M.G., M.S. Stankovic, I.D. Radojevic, O.D. Stefanovic and L.R. Comic et al., 2012. Biological effects, total phenolic content and flavonoid concentrations of fragrant yellow onion (Allium flavum L.). Med. Chem., 8: 46-51. DOI: 10.2174/157340612799278441

Hernandez, J.A. and M.S. Almansa, 2002. Short-term effects of salt stress on antioxidant systems and leaf water relations of leaves. Physiol. Plant., 115: 251257. DOI: 10.1034/j.1399-3054.2002.1150211.x

Hodges, D.M., M.J. DeLong, C.F. Forney and R.K. Prange, 1999. Improving the thiobarbituric acidreactive-sbtances for estimating lipid peroxidation in plant tissues containing anthocyanin and other interfering compounds. Planta, 207: 604-611. DOI: $10.1007 / \mathrm{s} 004250050524$

Hollosy, F., 2002. Effects of ultraviolet radiation on plant cell. Micron, 33: 179-197. DOI: 10.1016/S0968-4328(01)00011-7

Jordan, B.R., J. He, W.S. Chow and J.M. Anderson, 1992. Changes in mRNA levels and polypeptide subunits of ribulose 1,5-bisphosphate carboxylase in response to supplemental ultraviolet radiation. Plant Cell Environ., 15: 91-98. DOI: 10.1111/j.13653040.1992.tb01461.x

Kakani, V., G. Reddy and K.R. Zhao, 2003. Effects of ultraviolet radiation on cotton (Gossypium hirsutum) morphology and anatomy. Annal Bot., 91: 817-826. DOI: $10.1093 / \mathrm{aob} / \mathrm{mcg} 086$

Krauss, P., C. Markstadter and M. Rhederer, 1997. Attenuation of UV radiation by plant cuticles from woody species. Plant Cell Environ., 20: 1079-1085. DOI: 10.1111/j.1365-3040.1997.tb00684.x

Kumari, R. and S.B. Agrawal, 2010. Supplemental UV$\mathrm{B}$ induced changes in leaf morphology, physiology and secondary metabolites of an Indian aromatic plant Cymbopogon citratus (D.C.) Staph under natural field conditions. Int. J. Environ. Stud., 67: 655-675. DOI: 10.1080/00207233.2010.513828 
Li, J., T. Ou-Lee, R. Raba, R.A. Amundson and R.L. Last, 1993. Arabidopsis flavonoid mutants are hypersensitive to UV-B irradiation. Plant Cell, 5: 171-179. PMID: 12271060

Midgley, E.M., S.J.E. Wand and C.F. Musil, 1998. Repeated exposure of to enhanced UV-B radiation in successive increases developmental instability (fluctuating asymmetry) in a desert annual. Plant Cell Environ., 21: 437-442. DOI: 10.1046/j.13653040.1998.00274.x

Ravindran, K.C., A. Indrajith, P.V. Pratheesh, K. Sanjiviraja and V. Balakrishnan, 2010. Effect of ultraviolet-B radiation on biochemical and antioxidant defence system in Indigofera tinctoria $\mathrm{L}$ seedlings. Int. J. Eng. Sci. Tech., 2: 226-232.

Redha, A., N. Al-Mansour, P. Suleman, R Al-Hasan and M. Afzal, 2012. Modulation of antioxidant defenses in Conocarpus lancifolius under variable abiotic stress. Biochem. Syst. Ecol., 43: 80-86. DOI: 10.1016/j.bse.2012.02.026

Santos, I., F. Fidalgo, J.M. Ameilda and R. Salema, 2004. Biochemical and ultrastructural changes in leaves of potato plants grown under supplemental UV-B radiation. Plant Sci., 167: 925-935. DOI: 10.1016/j.plantsci.2004.05.035

Schnitzler, J., T.P. Jungblut, W. Heller, M. Köfferlein and P. Hutzler et al., 1996. Tissue localization of u.v.-B-screening pigments and chalcone synthase mRNA in needles of scot pine seedlings. New Phytol., 132: 247-258. DOI: 10.1111/j.14698137.1996.tb01844.x
Smith, J.L., D.J. Buritt and P. Bannister, 2000. Shoot dry weight, chlorophyll and UV-B absorbing compounds as indicators of a plant plants sensitivity to UV-B radiation. Annals Bot., 86: 1057-1063. DOI: $10.1006 /$ anbo. 2000.1270

Suleman, P., A. Redha, M. Afzal and R. Al-Hassan, 2013. Tempaerature-induced changes of malondialdehyde, heat shock proteins in relation chlorophyll fluorescence and photosynthesis in Conocarpus lancifolius (Engl.). Acta Physiol. Plant, 35: 1223-1231. DOI: 10.1007/s11738-012-1161-1

Wilson, K.E., J.E. Thompson, N.P. Huner and B.M. Greenberg, 2001. Effects of ultraviolet-A and ultraviolet-B induced accumulation of specific flavonoids in Brassica napus. Photochem Photobiol., 73: 678-684. DOI: 10.1562/00318655(2001)073<0678:EOUAEO>2.0.CO;2

Zhao, D., K.R. Reddy, V.G. Kakani, J. Read and J.H. Sullivan, 2003. Growth and physiological response cotton (Gossypium hirsutum) to elevated carbon dioxide and ultraviolet-B radiation under controlled environmental conditions. Plant Cell Environ., 26: 771-782. DOI: 10.1046/j.13653040.2003.01019.x 